\title{
Os saberes necessários à prática educativa e avaliativa em educação física escolar
}

\author{
The knowledge necessary for educational and evaluation practice in school physical education \\ Los conocimientos necesarios para la práctica educativa y de evaluación en la educación física \\ escolar
}

Recebido: 19/11/2021 | Revisado: 29/11/2021 | Aceito: 30/11/2021 | Publicado: 12/12/2021

\author{
José Áureo Soares de Jesus \\ ORCID: https://orcid.org/0000-0002-1565-8599 \\ Universidade Estadual da Bahia, Brasil \\ E-mail: áureo.69soares@gmail.com \\ Bárbara Plácida Souza Leite \\ ORCID: https://orcid.org/0000-0003-1798-001X \\ Universidade Estadual da Bahia, Brasil \\ E-mail: barbarapsleite@gmail.com \\ Igor dos Santos Ferreira \\ ORCID: https://orcid.org/0000-0003-3976-3083 \\ Universidade Estadual da Bahia, Brasil \\ E-mail: igorssfr1@gmail.com \\ João Paulo Farias Batista \\ ORCID: https://orcid.org/0000-0001-9817-1657 \\ Universidade Estadual da Bahia, Brasil \\ E-mail: joao.paulo110897@gmail.com \\ Luciane Barros Almeida \\ ORCID: https://orcid.org/0000-0003-2816-8545 \\ Universidade Estadual da Bahia, Brasil \\ E-mail: lucianebarrosalmeida@gmail.com \\ Carlos Luis Pereira \\ ORCID: https://orcid.org/0000-0001-7074-8661 \\ Universidade Estadual da Bahia, Brasil \\ Universidade Federal do Espírito Santo, Brasil \\ E-mail: carlosluispereira_331@ @otmail.com
}

\begin{abstract}
Resumo
O presente trabalho tem o intuito de apresentar a aplicação das metodologias e estratégias de ensino, mais concretamente adotadas na jornada docente. $\mathrm{O}$ delineamento deste trabalho se deu aos moldes da Pesquisa Bibliográfica de cunho qualitativo a partir de estudos de revisão de literatura sobre as praticas pedagógicas e métodos de avaliação. Dentro das concepções de Tardif (2002) a personalidade do professor é um componente essencial de seu trabalho. Vamos chamá-lo de trabalho investido ou vivido, indicando, com essa expressão, que um professor não pode "só fazer seu trabalho", ele deve também empenhar e investir nesse trabalho o que ele mesmo é como pessoa. Para vários autores, uma boa avaliação dos conteúdos podem trazer resultados benéficos e gradativos durante as aprendizagens e conhecimentos adquiridos pelos discentes, entretanto, essas avaliações precisam ser escolhidas e aplicadas no cotidiano do aluno de forma a conduzi-lo à aprendizagem, obtendo assim resultados satisfatórios a partir de sua avaliação e evitando análises errôneas e estresse por parte dos educadores e educandos.
\end{abstract}

Palavras-chave: Avaliação; Prática pedagógica; Aprendizagem.

\begin{abstract}
This work aims to present the application of teaching methodologies and strategies, more specifically adopted in the teaching journey. The design of this work was based on the Bibliographic Research of a qualitative nature, based on literature review studies on pedagogical practices and assessment methods. Within the concepts of Tardif (2002) the teacher's personality is an essential component of their work. Let's call it invested or lived work, indicating, with this expression, that a teacher cannot "just do his job", he must also commit and invest in this work what he is as a person. For several authors, a good content assessment can bring beneficial and gradual results during the learning and knowledge acquired by students, however, these assessments need to be chosen and applied in the student's daily life in order to lead them to learning, thus obtaining satisfactory results from its assessment and avoiding erroneous analyzes and stress on the part of educators and students.
\end{abstract}

Keywords: Assessment; Pedagogical practice; Learning.

\section{Resumen}

Este trabajo tiene como objetivo presentar la aplicación de metodologías y estrategias docentes, más específicamente adoptadas en el itinerario docente. El diseño de este trabajo se basó en la Investigación Bibliográfica de carácter 
cualitativo, a partir de estudios de revisión de literatura sobre prácticas pedagógicas y métodos de evaluación. Dentro de las concepciones de Tardif (2002) la personalidad del docente es un componente esencial de su obra. Llamémoslo trabajo invertido o vivido, indicando, con esta expresión, que un docente no puede "simplemente hacer su trabajo", también debe comprometer e invertir en este trabajo lo que es como persona. Para varios autores, una buena evaluación de contenidos puede traer resultados beneficiosos y graduales durante el aprendizaje y los conocimientos adquiridos por los estudiantes, sin embargo, estas evaluaciones deben ser elegidas y aplicadas en la vida diaria del estudiante con el fin de llevarlo al aprendizaje, obteniendo así resultados satisfactorios. de su valoración y evitando análisis erróneos y estrés por parte de educadores y estudiantes.

Palabras clave: Evaluación; Práctica pedagógica; Aprendizaje.

\section{Introdução}

A BNCC (Base Nacional Comum Curricular) apresenta a Educação Física como um componente curricular que tematiza as práticas corporais em suas diversas formas de codificação e significação social, entendidas como manifestações das possibilidades expressivas dos sujeitos, produzidas por diversos grupos sociais no decorrer da história. Para Soares et al. (1992), a Educação Física é uma prática pedagógica que, no âmbito escolar, tematiza formas de atividades expressivas corporais como: jogo, esporte, dança, ginástica, formas estas que configuram uma área de conhecimento que podemos chamar de cultura corporal. Neira (2019), diz que compreender a cultura corporal como um território de disputa implica planejar atividades de ensino que identifiquem a quem interessa a disseminação de uma determinada maneira de significar as práticas corporais e seus participantes.

Neste sentido, o presente trabalho tem o intuito de apresentar por meio de análises bibliográficas a aplicação das metodologias e estratégias de ensino, mais concretamente adotadas na jornada docente. Como o título sugere, ele é voltado aos saberes necessários à docência e as medidas de avaliação. Segundo Zabala (1998) "O conhecimento, aquele que provém da investigação, das experiências dos outros e de modelos, exemplos e propostas. Mas como podemos saber se estas experiências, modelos, exemplos e propostas são adequados?”. Como pilar principal para a construção de tal, o trabalho conta com os trilhos percorridos e os caminhos adotados por Zabala e outros autores com linhas de pesquisa similares e trabalhos voltados para determinado tipo de metodologia.

A fim de promover uma perspectiva diferente e eficaz no ensino e na avaliação, exposição e citação de leitura, análises e referências são os principais objetivos do trabalho: apresentar, comparar e estruturar estratégias que visam a garantia do processo de ensino aprendizagem, desta forma, possibilitar e estimular o pensamento crítico dos educandos neste processo. Para Kunz (2006), os alunos devem conseguir esclarecer os significados individuais que o movimento tem nas diferentes situações.

Fundamentalmente, a educação física escolar foi colocada na ordem do dia das discussões como objeto de estudos e reflexões acadêmicas, o que resultou na proposição de uma variedade de abordagens para o seu desenvolvimento, particularmente em forma de livros. Isso representou algo inimaginável até aquele momento, pois as elaborações teóricas sobre a educação física escolar eram muito incipientes e as publicações limitavam-se, basicamente, às coletâneas de atividades e exercícios, de jogos infantis a fundamentos técnicos de modalidades esportivas tradicionais. Em outras palavras, o que era disponível eram obras genéricas para a educação física como um todo, sem uma base teórica sólida que as pudessem caracterizar como abordagens específicas para o desenvolvimento da educação física escolar. Tani (2001).

A metodologia utilizada foi a consulta com base na pesquisa bibliográfica, enriquecida com um compilado contendo diversos autores com ideias similares ao se tratar da metodologia de ensino. A análise da pesquisa bibliográfica foi de fundamental importância para trazer à tona aspectos e características de similaridade entre os autores cujo trabalho tem como referência. Citações e referências são os grandes norteadores deste trabalho. 
Para Soares et al. (1992), o professor sentir-se-á apoiado, no desenvolvimento da sua reflexão, com os elementos teóricos sobre a concepção de currículo escolar vinculada a um projeto político-pedagógico que destaca a função social da educação física no contexto da educação escolar.

É esperado que após a leitura, seja possível que o leitor possa fazer uma assimilação com a realidade a qual está inserido, podendo utilizar futuramente como aplicação prática em sua jornada docente, vindo a promover possíveis mudanças, trazendo para uma nova geração um ensino benéfico, comprometido e libertador.

\section{Metodologia}

O delineamento deste trabalho se deu aos moldes da Pesquisa Bibliográfica de cunho qualitativo a partir de estudos de revisão de literatura sobre as práticas pedagógicas e métodos de avaliação. Pesquisa Bibliográfica é aquela baseada na análise da literatura já publicada em forma de livros, revistas, publicações avulsas, imprensa escrita e até eletronicamente, disponibilizada na Internet (Silva, 2001). Fonseca (2002), citado por Gerhardt e Silveira (2009), diz que a pesquisa bibliográfica procura referências teóricas publicadas com o objetivo de recolher informações ou conhecimentos prévios sobre o problema a respeito do qual se procura a resposta. Trata-se de uma pesquisa qualitativa, documental, utilizando como fonte bases de dados nacionais, livros, periódicos, sites e revistas ligadas à educação e processo ensino-aprendizado. Para Prodanov \& Freitas (2013), a pesquisa qualitativa é aquela que não pode ser traduzida em números, ou seja, não requer técnicas estatísticas para sua interpretação, além de possuir um vínculo entre objetividade e subjetividade. Severino (2013) classifica a pesquisa qualitativa como um tipo de abordagem metodológica que envolve diversas referências epistemológicas.

Para pesquisa, coleta de dados e seleção do conteúdo, foram utilizados os termos chaves, separadamente e/ou em conjunto: processo ensino-aprendizagem, práticas de ensino, prática educativa, práticas pedagógicas, processo avaliativo, avaliação diagnóstica, avaliação formativa, avaliação somativa.

\section{Revisão de Literatura}

\section{Saberes necessários à docência e processos de avaliação:}

Dentro das concepções de Tardif (2002), a personalidade do professor é um componente essencial de seu trabalho. Vamos chamá-lo de trabalho investido ou vivido, indicando, com essa expressão, que um professor não pode "só fazer seu trabalho", ele deve também empenhar e investir nesse trabalho o que ele mesmo é como pessoa. (Tardif, 2002)

Tardif (2004), destaca a existência de quatro tipos diferentes de saberes implicados na atividade docente: Saberes da Formação Profissional inicial e/ou continuada. Também se constituem o conjunto dos saberes da formação profissional os conhecimentos pedagógicos relacionados às técnicas e métodos de ensino (saber-fazer), legitimados cientificamente e igualmente transmitidos aos professores ao longo do seu processo de formação. Saberes Disciplinares São os saberes reconhecidos e identificados como pertencentes aos diferentes campos do conhecimento (linguagem, ciências exatas, ciências humanas, ciências biológicas, etc.). Esses saberes, produzidos e acumulados pela sociedade ao longo da história da humanidade, são administrados pela comunidade científica e o acesso a eles deve ser possibilitado por meio das instituições educacionais. Saberes Curriculares São conhecimentos relacionados à forma como as instituições educacionais fazem a gestão dos conhecimentos socialmente produzidos e que devem ser transmitidos aos estudantes (saberes disciplinares). Apresentamse, concretamente, sob a forma de programas escolares (objetivos, conteúdos, métodos) que os professores devem aprender e aplicar. Saberes Experienciais São os saberes que resultam do próprio exercício da atividade profissional dos professores. (Tardif, 2004)

Para Shulman (2005), o "conhecimento" sobre a "docência" é aquilo que os "professores deveriam saber, fazer, compreender ou professar para converter o ensino em algo mais que uma forma de trabalho individual e para que seja 
considerada entre as profíssões prestigiadas"; enquanto que para García (1992), é o conjunto de "conhecimentos, destrezas, atitudes, disposições que deverá possuir um professor do ensino".

Para Mizukami, o fenômeno educativo é humano, histórico e multidimensional: "Nele estão presentes tanto a dimensão humana quanto a técnica, a cognitiva, a emocional, sócio política e cultural”. Ao organizar sua exposição, utiliza-se de 5 abordagens: tradicional, comportamentalista, humanista, cognitivista e sociocultural. Não inclui a abordagem escolanovista, por considerar que seus pressupostos estão contemplados nestas outras abordagens. (Mizukami, 1992)

De acordo com Pimenta (1998), são três os saberes necessários ao exercício da docência, isto é: 1) saberes da experiência, que dizem do modo como nos apropriamos do ser professor em nossa vida; 2) saberes da área do conhecimento, conhecimentos específicos, conhecimentos científicos, pois ninguém ensina o que não sabe e; 3) saberes pedagógicos, saber pedagógico e saber didático, isto é, a relação professor-aluno, a importância da motivação e do interesse dos alunos no processo de aprendizagem, as técnicas ativas de ensinar etc.

Esteban \& Afonso (2010), alertam: o compromisso da prática docente em trabalhar para e com as diferenças de aprendizagem e inclusão dos alunos. Enfatizamos que uma avaliação ao serviço da promoção de aprendizagens qualifica e tece possibilidades de o outro se narrar, sem o engessamento de normas e padrões avaliativos que o rotulam como certo/errado, assumindo uma ação ética de os sujeitos avaliados falarem e, nessa troca, compreenderem os sentidos que produzem sobre o que aprendem nas aulas de EF.

Para Machado (2010), o papel do professor apresenta diversas invariantes. Segundo o autor, em qualquer circunstância, o professor é e sempre será: um mediador de conflitos de interesse, aproximando alunos e escola; um tecelão de significações, articulando conteúdos e contextos; um cartógrafo de relevâncias, ponderando conteúdos e inspirando mapas, que orientam caminhos; um construtor de narrativas fabulosas, revelando tesouros que alimentem projetos pessoais.

Para que os alunos vejam sentido no trabalho que irão realizar é necessário que conheçam previamente as atividades que devem desenvolver, não apenas como são como também o motivo pelo que foram selecionadas essas e não outras; que sintam que o trabalho que lhes é proposto está ao alcance deles e que seja interessante fazê-lo (Zabala, 1998). Zabala (1998), ainda completa afirmando que considerando estas condições, será necessário que os professores e professoras auxiliem os educandos para que saibam o que têm que se fazer, a que objetivos responde, que finalidade se persegue com que se pode relacionar e em que projeto global pode se inserir.

Zabala (1998), citado por Mendes (2005), relata que “a função das práticas avaliativas é interagir com os alunos com o intuito de compreender o processo de aprendizagem, identificando a origem das dificuldades, resistências e avanços".

Cunha (2004), por sua vez, tem enfatizado que "assumir a perspectiva de que a docência se estrutura sobre saberes próprios, intrínsecos à sua natureza e objetivos, é reconhecer uma condição profissional para a atividade do professor”.

Hoffmann (2000), em contato com os professores, percebe que o "fenômeno avaliação" é, hoje, um fenômeno indefinido. Ou seja, esta palavra tem diferentes significados tanto para os professores quanto para os alunos, entretanto, estes significados estão relacionados principalmente aos elementos que envolvem a prática avaliativa tradicional: prova, nota, conceito, boletim, recuperação, reprovação. Hoffmann (2000), conclui que dar nota é avaliar, fazer prova é avaliar, o registro das notas, denomina-se avaliação. Ao mesmo tempo, vários significados são atribuídos ao termo: análise de desempenho, julgamento de resultados, medida de capacidade, apreciação do "todo" do aluno. Quando questiono diretamente o significado da palavra avaliação recebo, por vezes, tantas definições quantos são os professores presentes nos encontros.

A avaliação escolar é parte fundamental do processo de ensino e aprendizagem, sendo considerados os conhecimentos, habilidades e atitudes, assimilação e aplicação por meio de métodos adequados. Devem manifestar-se em resultados obtidos nos exercícios, provas, conversação, didática, trabalho independente (Libânio, 1999). 
Para Mendez (2002), avaliamos apenas para confirmar ignorâncias e, como consequência qualificamos negativamente, aquele conhecimento torna-se fiscalizador, episódico, superficial, encobridor das próprias fragilidades e empobrecedor de uma atividade que em si deveria ser gratificante, além de estimulante para novas aprendizagens, para novas descobertas de conhecimento.

Na compreensão de Zabala (1998), toda forma de produção de conhecimento, ainda que a mais generalizada, pode e deve ser utilizada pelos professores e professoras como forma de incentivar os alunos a compreenderem um determinado conteúdo no seu aspecto conceitual. Entretanto, partindo dessa óptica, os diferentes tipos de conteúdos necessariamente carecem de uma adequação própria, levando educadores e educadoras à elaboração de uma prática metodológica que atenda as características de cada tipo de conteúdo.

Cada aluno é um ser individual, com características próprias, com formas diferentes de compreender o mundo e para, além disso, com formas diferentes de aprender um mesmo conteúdo, essas formas diferentes de aprendizado incluem tempo, abordagem e ritmo. Neste sentido, é necessário que os professores e professoras estejam munidos de ferramentas adequadas que os auxiliem na elaboração de intervenções que atendam as diferentes características do alunado, do mesmo modo, essas ações precisam ser monitoradas a todo instante com o objetivo de avaliar sua aplicabilidade e se necessário for, reorganizar o plano de intervenção quantas vezes forem necessárias.

Para Zabala (1998), é difícil conhecer os diferentes graus de conhecimento de cada menino e menina, identificar o desafio de que necessitam, saber que ajuda requerem e estabelecer a avaliação apropriada para cada um deles a fim de que se sintam estimulados a se esforçar em seu trabalho. Para isso, o professor deve ter a capacidade de conduzir seus alunos a realizarem as atividades propostas, sempre dando a eles suporte necessário, de acordo com a realização de cada tarefa, de maneira a conduzi-los e capacitá-los a exercitar sua autonomia.

Zabala (1998), traz à tona uma reflexão muito importante, quando ele sugere que os alunos estejam por dentro de todo seu processo de aprendizagem. O professor deve deixar sempre claro aos seus alunos quais os processos por qual eles irão passar. Ele deve destacar quais são os objetivos de cada atividade proposta, de quais meios se utilizar na execução das mesmas, e como eles serão avaliados no decorrer de todo processo. É de grande importância que o professor leve o aluno a se auto avaliar, conduzindo as suas aulas de maneira que não seja necessário que essa responsabilidade seja visto apenas como tarefa do professor. No entanto, a ajuda do professor é de suma importância junto aos alunos, a fim de proporcionar a eles uma autonomia progressiva, e desenvolver estratégias que promovem o controle e regulação da própria atividade, para que eles possam aprender a aprender.

Assim, pois, é preciso oferecer modelos da maneira de realizar o procedimento ou a técnica, é preciso oferecer um apoio constante na realização de cada um dos passos e é preciso retirar progressivamente estas ajudas até que os alunos sejam capazes de atuar de forma autônoma.

Zabala (1998), ainda complementa no que se diz necessário que os alunos conheçam e se apropriem dos critérios e dos instrumentos que os professores utilizam para avaliá-los. Que possam conhecer desde o princípio o que se quer deles, que sentido tem este objetivo, de que meios de ajuda disporão que pautas e instrumentos são utilizados para conhecer suas aprendizagens e que critérios avaliativos serão aplicados. Neste sentido, ganha uma importância crucial a integração de atividades que promovam a auto avaliação dos alunos. É preciso recusar fórmulas em que o controle e a avaliação recaem exclusivamente nos professores, sobretudo em situações e momentos alheios aos processos individuais de aprendizagem.

Por outro lado, as situações de atuação conjunta favorecem o processo de autonomia progressiva e, portanto, a aquisição progressiva de estratégias de controle e regulação da própria atividade, imprescindíveis para promover a capacidade de aprender a aprender. 
Para Fernandes (2000), na sociedade em que vivemos exige-se que se aprenda ao longo de toda a vida, e é bom que todos estejamos preparados para sermos avaliados em permanência, para podermos evoluir, para que haja justiça nas relações de trabalho, para sermos uma sociedade meritocracia e não uma sociedade clientela onde uma boa cunha vale mais do que uma competência comprovada.

Qualidade, numa perspectiva mediadora da avaliação, significa desenvolvimento máximo possível, um permanente "vir a ser", sem limites pré-estabelecidos, embora com objetivos claramente delineados, desencadeadores da ação educativa. Não se trata aqui, como muitos compreendem, de não delinearmos pontos de partida, mas sim de não delimitarmos ou padronizarmos pontos de chegada (Hoffmann, 1999).

Assim, por exemplo, se um dos valores que se quer transmitir é a solidariedade, não basta propor atividades de debate e reflexão sobre comportamento de cooperação em diferentes ambientes e espaços sociais, mas será necessário que na aula se viva num clima de solidariedade onde existam possibilidades de atuar segundo estes princípios. Uma observação: este clima será o resultado das imagens que os próprios professores transmitem. (Zabala, 1998)

Como afirma Hébrard (2002), a necessidade de privilegiar determinados conhecimentos, quando comparados com outros, é uma questão que demarca o processo de escolarização das disciplinas. De acordo com o autor, a escola se constitui como um lugar em que as práticas culturais valorizadas se referem àquelas que são organizadas por meio de diferentes sistemas simbólicos, materializados em dispositivos de instrução. Sob essa perspectiva, ela institui a leitura e a escrita como aprendizagens anteriores a todas as disciplinas.

\section{Concepção de avaliação}

A avaliação é um instrumento e uma ação extremamente complexa, e faz parte do mundo escolar, geralmente quando se fala de avaliação, entende-se que é um método prioritário e único, no qual é produzido pelos resultados obtidos pelos alunos. Ao longo da história, a avaliação foi utilizada de diferentes maneiras, funções, objetivos e métodos e somente é realizada ao final do processo de aprendizagem para mensurar seu produto final, como ferramenta de coleta de "níveis" Luckesi (2000) classifica os alunos como "bons", "regulares" ou "ruins" sem considerar a autorreflexão no processo.

Contudo, a responsabilidade da avaliação não é apenas a habilidade do professor, mas todos os elementos do processo educacional (alunos, pais e administradores) para os mesmos, a avaliação é o processo onde avalia o grau de aproveitamento dos alunos na disciplina, portanto, a avaliação é considerada uma ferramenta de reconhecimento e qualificação. A avaliação pode e deve oferecer ao professor elementos para uma reflexão contínua sobre a sua prática, no que se refere à escolha de competências, objetivos, conteúdos e estratégias (Darido \& Souza Júnior, 2007). Ainda, conforme Darido \& Souza Júnior (2007), a avaliação deve mostrar-se útil para as partes envolvidas - professores, alunos e escola, e não deve ser utilizada como instrumento de pressão e castigo, ao contrário, deve contribuir para o autoconhecimento e para a análise das etapas já vencidas, no sentido de alcançar objetivos previamente alcançados.

Ensino e aprendizagem estão inter-relacionados e juntos formam uma parte integrante da sala de aula. Portanto, existem dois processos de avaliação, um é a forma como os alunos aprendem e o outro é a forma como os professores ensinam. Os métodos tradicionais de avaliação centram-se nos resultados obtidos pelos alunos.

Porém, na literatura pedagógica, existem algumas afirmações de reforma educacional sugerindo uma avaliação irrestrita, que não se limita a avaliar somente os resultados alcançados pelos alunos. No entanto, a avaliação vai além da medição, existe um processo em que os alunos acompanham e correspondem ao processo coletivo, de progressão pessoal, ensino e aprendizagem, elementos que juntos somam à avaliação, na qual cobre o aspecto da qualidade, que é muito mais difícil, e a partir disso envolve objetivos, atitudes, políticas e valores subjetivos. 


\section{Métodos de avaliação}

De acordo com Zabala (1998) a escola tem como prioridade qualificar e aprovar os alunos desde crianças, com o intuito de que se preparem melhor para o futuro, de forma a escolher o melhor desde a educação escolar até a universidade. No entanto, a função social do ensino não é apenas promover os alunos a serem considerados mais adequados para as universidades, mas também incluir outras questões e dimensões da personalidade.

Nos dias atuais, nas escolas públicas e privadas do Brasil, do ensino fundamental ao ensino superior, ainda sim há realização de exames escolares mensurando resultados e não avaliando literalmente a aprendizagem de cada aluno. Segundo Luckesi (2003), historicamente, passamos a denominar a prática de acompanhamento da avaliação da aprendizagem do educando de "Avaliação da aprendizagem escolar", mas, na verdade, continuamos a praticar "exames". O autor chama essa prática de ensino de Pedagogia do Exame. Segundo ele, ainda existe a prática desses métodos nas escolas. Ainda, para este autor, também pode-se constatar os resquícios desse tipo de pedagogia de exames em algumas práticas avaliativas nacionais, como o Exame Nacional do Ensino Médio-Enem, para ele, deste modo fortalece ainda mais a cultura do exame e não a cultura da avaliação.

Para Darido (2003), no contexto escolar a avaliação em Educação Física é duramente criticada porque vem estimulando uma prática discriminatória aos interesses da classe trabalhadora.

Zabala (1998), declara que quando a formação é de cunho integral o objetivo principal do ensino, é potencializar as habilidades dos alunos, não apenas as cognitivas. O conteúdo de aprendizagem a ser avaliado não é apenas um conteúdo relacionado às necessidades voltado ao percurso universitário. É preciso também considerar conceitos, procedimentos e atitudes que promovam equilíbrio e autonomia pessoal, relacionamento interpessoal e inclusão social no processo.

Para Manoel (1994) O comportamento humano constitui-se num sistema complexo e como tal apresenta vários elementos em constante interação.

\section{Tipos de Avaliação}

\section{Avaliação Formativa}

A avaliação formativa ou formadora, é projetada para considerar as avaliações realizadas em diferentes momentos e etapas, e para fornecer aos alunos um tipo de feedback sobre seu progresso, avanço ao decorrer do processo. De acordo com Hadji (2001), a avaliação formativa é ideal, pois pode ser útil diante de situações pedagógicas, uma vez que permite ao aluno criticar a realidade, debater assuntos, fazendo com que o mesmo se imponha, questione e reflita sobre alguma situação.

Zabala (1998) em relação a essa mesma avaliação, parte de uma perspectiva uniformizadora e seletiva, no qual o importante são alguns resultados, que possibilitem aos alunos chegar à escola com uma bagagem determinada e diferenciada em relação às suas experiências de vida de acordo com a cultura social e o ambiente familiar em que vivem, suas características pessoais são uma condição. Nesse quadro, a avaliação deixa de ser estática e a análise dos resultados passa a ser um processo. O primeiro passo nesse processo é entender o que cada aluno sabe, se ele sabe fazer e como fazer.

A avaliação é um processo e a primeira etapa é chamada de avaliação inicial. Não apenas os alunos são diferentes em cada situação, mas sua experiência educacional por sua vez também é diferente, e não há de se repetir para outros alunos. Com isso, Zabala relata a importância de ajustar as diferentes variáveis educacionais de acordo com as necessidades de cada aluno. De forma, a entender como cada aluno aprende ao longo do processo. 


\section{A avaliação a partir de determinados conteúdos}

Zabala (1998), em seu livro relata 4 tipos de avaliações de conteúdos sendo eles: factuais, conceituais, procedimentais e atitudinais, sendo cada um deles com suas especificações. Ao decorrer de cada uma dessas avaliações o autor relata a sua visão sobre cada conteúdo.

Avaliação de conteúdos factuais é relacionado aos fatos, no qual envolve a conexão entre fatos e conceitos. Isso permite que o conhecimento se transforme em ferramentas para explicar certas situações. Os conceitos também podem ser compreendidos por meio dos fatos, como o conceito de capital, o país e os processos históricos; seu objetivo é permitir que os alunos compreendam os fatos, tornando o conhecimento significativo, e não apenas dados desconectados.

Avaliação de conteúdos conceituais se trata de aprendizagem de conceitos, qual é a compreensão dos alunos sobre determinados conceitos. Essa compreensão muitas vezes é limitada, pois é difícil saber e dizer que a aprendizagem de um conceito está completa. A partir disso, o que se pode fazer é estabelecer certo grau de conceituação, onde é necessário determinar o grau, a profundidade e o nível de compreensão, e propor atividades que os alunos possam expressar sua compreensão e aprendizagem.

Avaliação de conteúdos procedimentais se dá ao saber fazer, praticar literalmente, observar o conhecimento e domínio desse saber fazer, no qual só pode ser analisado quando os alunos aplicam esses conteúdos. O que define a aprendizagem não é o conhecimento, mas o domínio de colocá-la em prática.

Avaliação de conteúdos atitudinais nesse tipo de avaliação é muito complicado determinar o nível de aprendizagem de cada aluno. Onde o objetivo deste conteúdo é realmente compreender os valores, necessidades e atitudes dos alunos em determinadas situações.

\section{Considerações Finais}

Todavia, constatou-se que os processos avaliativos, ainda que sejam variados, se correlacionam com à prática pedagógica dos professores e professoras no âmbito escolar, considerando que avaliar seja um ato de diagnóstico contínuo, na qual não deva ser apenas classificatório, excludente e seletivo. Do mesmo modo, tais processos, podem resultar de uma limitação decorrente do pouco conhecimento e/ou compreensão dos processos de avaliação na área escolar.

Para vários autores, uma boa avaliação dos conteúdos podem trazer resultados benéficos e gradativos durante as aprendizagens e conhecimentos adquiridos pelos discentes, entretanto, essas avaliações precisam ser escolhidas e aplicadas no cotidiano do aluno de forma a conduzi-lo à aprendizagem, obtendo assim resultados satisfatórios a partir de sua avaliação e evitando análises errôneas e estresse por parte dos educadores e educandos.

O presente estudo se configura pertinente, pois pode apresentar-se como um ponto de partida para que a comunidade escolar compreenda e selecione a melhor prática pedagógica e/ou avaliativa de acordo com o publico alvo, no entanto, outros estudos e propostas devem ser buscados e/ou desenvolvidos conforme a necessidade/realidade de cada escola, pois, para Zabala (1998) a escola precisa desenvolver estratégias para a formação integral dos estudantes, essas estratégias permeiam nos métodos avaliativos e de ensino aprendizagem, a fim de minimizar o universo do ensino tradicionalista e buscar novas possibilidades para um ensino inovador. Pode-se afirmar que os professores e professoras devem estar cientes da existência dos três principais tipos de avaliação e seus objetivos. A avaliação diagnóstica permite conhecer o aluno, seus gostos, seus hábitos e preferências; a formativa permite ajustar o processo de ensino-aprendizagem à realidade de aprendizado do aluno; e a 
somativa, permite classificar o nível de aprendizado dos alunos.

\section{Referências}

Brasil. (2018) Ministério da Educação. Base Nacional Comum Curricular. Brasília.

Cunha, M. I. (2004) A docência como ação complexa: o papel da didática na formação de professores. Curitiba. Editora: Champagnat.

Darido, S. C. (2003) Educação física na escola: questões e reflexões. Rio de Janeiro. Editora: Guanabara Koogan S.A.

Darido, S. C. \& Souza Junior, O. M. (2007) Para ensinar educação física: Possibilidades de intervenção na escola. Campinas. Editora: Papirus

Garcia, C. M. (1992) Como conocen los profesores la materia que enseñan: algunas contribuciones de la investigación sobre conocimiento didáctico del contenido. Ponencia presentada al Congreso Las didácticas específicas en la formación del profesorado, Santiago de Compostela, España, 6-10 jul. 1992.

Gerhardt, T. E. \& Silveira, D. T. (2009) Métodos de pesquisa/coordenado pela Universidade Aberta do Brasil - UAB/UFRGS e pelo Curso de Graduação Tecnológica-Planejamento e Gestão para o Desenvolvimento Rural da SEAD/UFRGS. - Porto Alegre. Editora: UFRGS.

Hadji, C. (2001) Avaliação desmistificada. Porto Alegre. Editora: ArTmed.

Hoffmann, J. M. L. (1999) Avaliação mediadora: uma prática em construção da Pré-escola à Universidade. (17ª ed.) Porto Alegre. Editora: Mediação.

Kunz, E. (2006) Didática da educação física 1. (4ª ed.) Ijuí. Editora: Unijuí

Libâneo, J. C. (1999) Didática. (15ª Ed.) São Paulo. Editora: Cortez.

Luckesi, C. C. (2000). Avaliação da Aprendizagem Escolar: estudos e proposições. (10ª ed.) São Paulo. Editora: Cortez.

Luckesi, C. C. (2003) Avaliação da aprendizagem na escola: reelaborando conceitos e recriando a prática. Salvador. Editora: Malabares.

Machado, N. J. (2010) Educação: microensaios em mil toques. (2 ${ }^{\mathrm{a}}$ ed.) São Paulo. Escrituras Editora.

Manoel, E. J. (1994) Desenvolvimento motor: Implicações para a educação física escolar I. Rev. paul. Educ. Fís., São Paulo, 8(1):82-97, jan./jun. 1994.

Méndez, J. M. A. (2002) Avaliar para Conhecer, examinar para Excluir. Porto Alegre. Editora: Artmed.

Neira, M. G. (2019) Educação física cultural: inspiração e prática pedagógica. (2ª ed.) Jundiaí. Editora: Paco.

Pimenta, S. G. (1998) Formação de professores: saberes da docência e identidade do professor. Campinas-SP. Editora Papirus.

Prodanov, C. C. \& Freitas E. C. (2013) Metodologia do trabalho científicos. (2 ed.) Novo Hamburgo. Editora: Feevale.

Silva, E. L. (2001) Metodologia da pesquisa e elaboração de dissertação. (3 ${ }^{\mathrm{a}}$ ed.) Florianópolis.

Severino, A. J. (2013) Metodologia do trabalho científico. (1 $1^{\text {a }}$. ed.) São Paulo. Editora: Cortez.

Shulman, L. S. (2005) Conocimiento y enseñanza: fundamentos de la nueva reforma. Profesorado. Revista de Currículum y formación del profesorado, 9, 2 , p. 1-30.

Soares, C. L. et al. (1992) Metodologia do ensino da educação física. (1 ${ }^{\text {a }}$ ed.) São Paulo. Editora: Cortez.

Tani, G. (2001) Educação física na educação infantil: Pesquisa e produção do conhecimento. Rev. paul. Educ. Fís., São Paulo, supl.4.

Tardif, M. (2002) Saberes docentes e formação profissional. Petrópolis. Editora: Vozes.

Zabala, A. (1998) A prática educativa : como ensinar. Porto Alegre. Editora: ArtMed. 